\title{
Is Rebabilitation of the Rural Disabled a Realistic Objective?
}

\author{
PAM MCLAREN
}

\section{INTRODUCTION}

In considering the feasibility of rehabilitation of the rural disabled there are initially three concepts which should be addressed. These are rehabilitation, disablement, and rural disability.

\section{REHABILITATION}

'Rehabilitation' is usually defined as the third phase in medicine (prevention being the first, and curative care the second). The 1969 WHO Expert Committee on Medical Rehabilitation' defined 'rehabilitation' as follows:

the combined and coordinated use of medical, social, educational, and vocational measures for training or retraining the individual to the highest possible level of functional ability'.

Evidently, since 1969, the concept of rehabilitation has broadened and the world is now used to refer to a variety of programmes. However, a closer look at the above definition of rehabilitation shows that the definition relates mainly to interventions aimed at the individual and neglects those aimed at changing the factors in his immediate surroundings in the society as a whole. ${ }^{2}$

In 1981 a WHO expert Committee recommended the use of the following definition for rehabilitation:

"Rehabilitation includes all measures aimed at reducing the impact of disabling and handicapping conditions, and at enabling the disabled and the handicapped to achieve social integration.

Rehabilitation aims not only at training disabled and handicapped persons to adapt to their environment, but also at intervening in their immediate environment and society as a whole, in order to facilitate their social integration. The disabled and handicapped themselves, their families, and the communities they live in should be involved in the planning and implementation of services related to rehabilitation. ${ }^{3}$

Pam McLaren, M.SC. (Occup. Ther.)

Occupational Therapist at Manquzi Hospital, Kwa Zulu and doctoral student of the Department of Community Health, University of the Witwatersrand, Johannesburg

Paper read at the Biennial Conference of the South African National Council for the Blind, October 1985, Pretoria. Reprinted with permission from the official journal of SANCB - Infama, February 1986
This definition includes the preventive and curative measures which were deficient in the 1969 definition and which are important in reducing the disability problem.

The emergence of medical rehabilitation in the early part of the 19th century saw the development of institution-based rehabilitation (IBR) as the modus operandi. Most countries of the world have today at least one active rehabilitation institution. These institutes have achieved many excellent results and have had a great influence on the attitude towards rehabilitation. However, the impact on the disability problem as a whole has been small.

Since 1969 there has been increasing criticism regarding the deficiencies in rehabilitation services. ${ }^{4}$

Although the goal of providing sufficient rehabilitation facilities for all those in need has been achieved in a few very developed countries, it is evident that it will not be achieved in the developing countries. ${ }^{1}$

An example of why this will not be possible is given below: It was recently recommended that rehabilitation services be set up in the capital city of a country in Africa. Figures of manpower needs (in 11 different occupations) and of patient turnover were provided. When the figures were studied it was found that if the entire health budget for the country were utilized solely for rehabilitation services, it would take 60 years to develop the necessary manpower and about 200 years to provide the present needy population. with the desired amount of care.

The impracticality of using IBR as the modus operandi in developing countries is well illustrated by this example. The deficiencies in the conventional approach to rehabilitation can be looked at in the areas of:

a. planning deficiencies - partly due to lack of adequate statistics of the problem,

b. deficiencies in the content of services - partly due to economic constraints,

c. coordination deficiencies - often caused by professional 'terrorialism'.

WHO concluded that 'owing to the large gap between actual needs and the potential possibilities of meeting them by utilizing present methods of providing services, present policies must be changed and a new set of solutions more in keeping with the actual situation and the available resources must be created and implemented'. ${ }^{1}$

I will come back to this later on. 


\section{DISABLEMENT}

Much of the problem of inadequate statistics with regard to disability has been the lack of uniformity in defining the different levels of severity of disability.

Wood stated that 'Disablement is a compound concept concerned with the consequences of disease and illness'. 5 He went on to point out that the medical model of disease is concerned with the intrinsic situation, the occurrence of something abnormal within the individual. This is followed by exteriorization of the problem, where someone becomes aware of the abnormal occurence. In turn this experience if objectified as performance or behaviour undergoes alteration, everyday activities may become restricted, and the whole process can trigger psychological responses, which is referred to as illness behaviour. Finally, these occurrences are socialized as the awareness of altered performance of behaviour leads to the individual being placed at a disadvantage relative to others in society. This brief outline of the development of illness has been condensed from the International Classification of Impairments, Disabilities, and Handicaps. ${ }^{6}$ Its relevance is that it helps to establish the foundation of a conceptual model of disablement (Figure 1). ${ }^{5}$

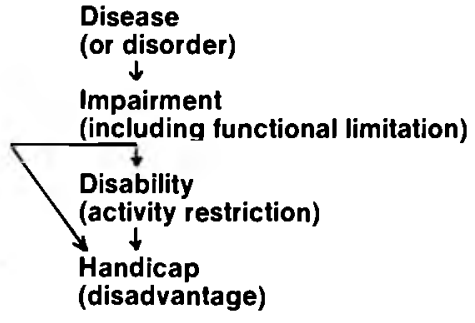

intrinsic situation

Exteriorized

Objectified

Socialized

Fig. 1.

In brief then, impairment refers to disfunction of bodily parts or organs. Disability is a characteristic of an individual, describing aberrations in normal performance whether physical, emotional, mental or social. Handicap is the social consequence of disability, i.e. the disadvantage compared with other individuals. ${ }^{7}$

It is important to consider how impairments and disabilities give rise to handicap. Medical and remedial treatment tends to concentrate on the individual, but disadvantage arises from interaction with that person's situation. This requires that thought be given to the environment, both physical and social, and to the resources to which the individual has access. The critical property of handicap is its relativity, the discordance between the individual's performance and the expectation of his 'society'.s

Taking into account the various estimates of disability, the evidence suggests that about a third of the population is impaired in some way, a third of those with impairments are disabled to some extent, and a third of the latter experience sufficiently severe restriction in activity as to be handicapped. ${ }^{5}$

Now we come to the situation found in developing rural areas.

\section{RURAL DISABILITY}

During the International Year of Disabled Persons 1981, many countries initiated surveys to establish more accurate figures of the numbers of disabled people. In industrial countries, many factors were established regarding disability, e.g. the association between disability and age. However, in the industrialized countries it is recognized that the available statistics are inadequate and there are still many questions which have not been answered.

In developing countries still very little is known regarding the extent of the disability problem as well as the age and sex structure of the disabled population. Extrapolating the findings from developed countries gives an indication of the immense resources which will be needed to deal with the problem over time, taking into consideration that during the next 50 years the population of the developing countries is expected to treble. ${ }^{8}$

Properly conducted disability surveys cost a great deal of money which developing countries can ill afford. In addition, many developing countries doubt, with reason, whether it is ethical to count disabilities without offering treatment or relief. ${ }^{8}$

A recent Impairment Disability and Handicap Study in $\mathrm{KwaZulu}{ }^{9}$ which obtained information on a sample of 1659 people and cost R20,000, gave an overall crude prevalence rate for motor impairment of $51 / 1000$. There was a marked increase with age, $6 \%$ were between 20 40 years, $27 \%$ were between $40-50$ years, and $67 \%$ were over 60 years. The female age specific motor impairment rates for walking disability are given in Table 1 .

Table 1. Female age-specific motor impairment rates per 1000 for walking disability

$\begin{array}{cc}\text { Age } & \text { Motor impairment rate/1 } 000 \\ 0-10 & 13 \\ 11-20 & 15 \\ 21-30 & 26 \\ 31-40 & 36 \\ 41-50 & 86 \\ 51-60 & 96 \\ >-60 & 378\end{array}$

As can be seen there is a gradual increase in motor impairment associated with walking disability with age and a dramatic increase over 50 years $(277 / 1000)$.

The same study showed a crude prevalence rate of $9 / 1000$ for visual impairment including blindness. This was divided into $5 / 1000$ for blindness (vision less than $6 / 60$ and 4/1 000 for visual impairment (vision between $6 / 29-6 / 60$ ). Although the rates were small in comparison with the motor rates, it was significant that the rate for blindness as a result of microphthalmus was $2 / 1000$. (Micropthalmus is a genetic condition and the rate in a normal population is $0,5 / 1000$.)

No similar studies using impairment and disability as defined here have been done in rural areas and it is therefore impossible to compare disability and impairment prevalence rates. However, this study demon- 
strated that in a subsistence dependent rural area in South Africa walking disability is a major problem, and that blindness among young people was mainly due to a genetic condition. ${ }^{9}$ According to surveys sponsored by WHO, in some developing countries it has been estimated that between 7 and 10 percent of the population in these countries is disabled. Disabled persons form the most severely underprivileged group in the societies of developing countries. ${ }^{10}$ WHO has recognized that :. . the massive disability is, clearly, in developing countries', ${ }^{6}$ and Wilson ${ }^{8}$ stated that 'It is among the poorest communities in the developing countries that poverty breeds disablement and disablement breeds poverty, a vicious circle that the poorer countries can least afford. These communities are the target of every rational development programme - underprivileged, underserved, undernourished, at the bottom of every economic and social heap. Diseases long controlled elsewhere still flourish and bring with them not only death but lifelong disability, e.g. leprosy.

Resources for health care are still scarce in most developing countries. This is especially true in rural areas where, in many countries, \pm 80 percent of the population live. In SA the 1970 census indicated that $70 \%$ of the SA black population live in homeland and white farm areas (i.e. rural). " Rehabilitation services are among the least developed and it has been calculated that 98 percent of the disabled have no access to services in their lifetime. For those few who now receive services, these are mainly in the form of institutionbased rehabilitation (IBR).

IBR is concentrated in the cities and only on rare occasions available to rural populations. Institutions are highly specialized and expensive. They are dependent for efficient running on teams of highly trained professionals who work according to Western standards. Their methods include use of sophisticated technology. Institutions are usually residential and require a great number of staff.

Plans to extend IBR in order to cover population needs have usually met with economic problems. An attitude commonly found is that services for the disabled are a luxury only a rich country can afford. 10

All this has indicated that a different approach is required with regard to rehabilitation in developing rural areas, and SA is considered a developing country. It is evident that the conventional approach in which disabilities were divided into impairment categories, e.g. Physical, Deaf, Blind, Mental retardation, etc. is not appropriate in rural areas and that a multi-disciplinary approach is required. $1 \mathrm{t}$ is not only the approach to the disability problem which must be multi-disciplinary but also to the next concept which I would now like to introduce; that of Community-based Rehabilitation (CBR).

\section{COMMUNITY-BASED REHABILITATION (CBR)}

CBR is a concept closely related to primary health care and forms an integral part of the programme to develop health for all by the year 2000 .
'Community-based rehabilitation involves measures taken at the community level to use and build on the resources of the community, including the impaired, disabled, and handicapped persons themselves, their families, and their community as a whole. '10

CBR promotes community responsibility and reliance on local resources. Family and community members are involved in the essential training for their own disabled, using local technology. A referral system is set up to meet needs that cannot be locally dealt with. To make it effective, training is done in the following way.

Rehabilitation programmes of proven value are chosen and these are broken down into modules, arranged in so called 'training packages' (TPs). TPs include a short description for the person who introduces and supervises the training, a detailed description of the various training steps and an evaluation sheet. The language is simple and the text supported by many drawings. The TPs are given directly to the disabled person and to the family members responsible for the daily training.

CRB is carried out in the following manner:

A 'local supervisor' is recruited from the community and trained. The local supervisor identifies the disabled by making house-to-house visits. The disabled and their families are motivated to take part in CBR. A 'trainer', normally a family member of the disabled or a friend, receives instructions on how to do the training. Practical demonstrations are given and the local supervisor checks that the training is done correctly. The results are evaluated together with the disabled and the trainer. ${ }^{10}$

The modules used in CBR have been compiled into a WHO manual "Training the Disabled Person in the Community'. ${ }^{12}$ The manual contains booklets for 6 groups of disabled persons; i.e. those who have fits, hearing and speech difficulties, learning difficulties, moving difficulties, seeing difficulties, and persons with strange behaviour. Each module contains the appropriate TPs, instruction and evaluation sheets. In addition, there are four guides: for policy makers and planners, for local supervisors, for community leaders, and for teachers.

Now is this approach feasible in SA? CBR has been used in different parts of the world, e.g. Botswana, Burma, India, Mexico, Nigeria, Pakistan, the Phillipines, Saint Lucia (Caribbean), and Sri Lanka. It has been proven to be technically viable, effective, feasible, and appropriate in all the different settings in which it has been used. It has been estimated to be economically maintainable and organizationally feasible if implemented as a component of primary health care and community services.

The manual has been adapted and an improved version was published in 1983.

The SA Federal Council for Rehabilitation of the Disabled has taken the initiative by becoming involved in a pilot project which it is hoped will commence in 
1986 in KwaZulu. Funding has been made available by the Anglo-American Chairman's Fund for the adaptation of the WHO Manual to local rural conditions in $\mathrm{K}$ waZulu and for it to be translated into Zulu.

The manual will include, in its development, the testing of the material on Therapy Attendants who have been involved in dealing with rural disability for 5 years at Manguzi Hospital.

The concept of Rehabilitation Assistants is the final one which I would like to deal with in this paper.

\section{REHABILITATION THERAPISTS}

Irwin (1982) proposed the use of paraprofessional workers, backed by specialized government facilities, to provide the basic services, for disability prevention and community based rehabilitation. Ideally, he stressed that these community level workers should come from the areas in which they work. They should be trained to work in their own villages or areas and thus, they would have to answer directly to their constituencies. 13

The name given to the worker under discussion is a Rehabilitation Therapist. It is the accepted term for a non-professional worker involved with rehabilitation and supervised by a professional therapist. ${ }^{14}$

In KwaZulu a four-tiered rehabilitation delivery system for rural health services has been proposed (Figure 2).

\section{Dept \\ of Health \\ Control Therapy \\ Post}

\section{Referral Hospitals \\ 10 Physio 10, OT \\ 3 Speech Therapy Supervisors}

Outlying Rural Hospitals

1 Rehabilitation Therapist

Community

Local Supervisors/Community Health Workers/Trainers

Fig 2. Proposed four-tiered rural rehabilitation delivery system.

Progress towards success in the prevention of disability and in the delivery of rehabilitation to those at risk in rural areas will require significant changes in established habits. People everywhere resist change.

It must be understood that new approaches are one thing but new programmes are another and that the programmes will only be accepted if there is a clear understanding and involvement on the part of all the groups and of the individuals at risk. Community participation is essential and only possible where the processes of planning and administration are decentralized to the community level - the challenge is to identify, understand and work with the existing community systems. ${ }^{13}$

'In its fullest sense, community participation is the method of allowing people to marshal and channel their energies and abilities to improve their lives. It requires organization and motivation; and the outsider's role is to cajole and inspire, to encourage the community to take the initiative. When communities begin to understand what causes disabilities among them, they will be the first to need to develop activities to bring about prevention. ${ }^{1 / 3}$

With regard to professionals and organizations serving the disabled, it is essential that they understand, accept, and involve themselves in the process of simplifying the manpower structure in rehabilitation services. The costs of health care services have reached a level that reductions will have to be made whether we like it or not. The professionals must be willing to discuss and prepare themselves for the future changes and these changes will then be less traumatic. ${ }^{15}$

\section{CONCLUSION}

l am sure there is no doubt in your minds about the need to change. We have posed the question, 'Is Rehabilitation of the Rural Disabled a realistic objective'. trust that it has been answered in the affirmative.

However, we need imagination, courage, perseverance, and above all, faith in the ideal of providing Rehabilitation for All (RFA). The RFA philosophy stresses the right to rehabilitation and its relationship to the right to self-sufficiency. It demystifies the rehabilitation process and places it in the hands of disabled people themselves.

As World Health points out in their May 1984 Journal, ${ }^{16}$ 'No single approach to a RFA programme including technology, delivery system and management - would be applicable to every corner of the earth. Each country should design its own plan, based on experience from abroad and lessons learned at home. RFA has so far been introduced in about 25 countries. Today it covers total populations of more than a million people. It requires only a fraction of the budget needed for traditional institutional rehabilitation.

Death and illness have always occupied the health authorities but the third dimension - disability - has yet to attract the attention it deserves.

It has been said that the quality of life among disabled persons in developing countries is a matter of great concern to the international community. And here in South Africa the initiative to improve the quality of life of the rural disabled has been taken up by the SA National Council for the Blind, and the Federal Council for Rehabilitation of the Disabled.

I hope that my paper has emphasised the importance of supporting the initiative and has affirmed that by using the Community Based Rehabilitation Approach, Rehabilitation of the Rural Disabled is a realistic objective.

\section{References used in the Preparation of this Paper}

1. WHO Technical Report Series No. 497, Geneva 1972.

2. WHO, Disability prevention and rehabilitation. WHO A29/InfDoc/1.28 April 1976.

3. WHO, Disability prevention and rehabilitation. Report of the WHO Expert Committee on Disability Preven- 
tion and Rehabilitation. WHO Technical Report Series 668. WHO, Geneva, 1981.

4. Report of a meeting of experts, International Society for Rehabilitation of the Disabled, Ireland, September 1969.

5. Wood PHN. Prospects for Control. In: Disability Prevention: the Global Challenge (ed. Sir John Wilson). Oxford University Press, Oxford 1983.

6. WHO International Classification of Impairments, disabilities, and handicaps. WHO, Geneva 1980.

7. WHO Regional Office for Europe. The Age Factor. In: Disability Prevention: A Global Challenge (Ed. Sir John Wilson). Oxford University Press, Oxford 1983.

8. Wilson John. The scale of the problem. In : Disability Prevention: A Global Challenge (Ed. Sir John Wilson). Oxford University Pres, Oxford 1983.

9. McLaren PA, Gear JSS, Irwig LM. Prevalence of motor impairment and disability in a rural community in $\mathrm{K}$ waZulu (in preparation).

10. WHO Community Based Rehabilitation. WHO RHB/IR/82.1. Report of the WHO Inter-regional Consultation Sri Lanka, July 1982.

11. SA Institute of Race Relations 1978: A survey of race relations in SA, Johannesburg.

12. Helander E, Mendis P, Nelson G. Training disabled people in the community. A manual for community based rehabilitation for developing countries. Geneva, WHO I983.

13. Irwin Michael HK. Delivery and community participation. In: Disability Prevention: the global challenge (Ed. Sir John Wilson) Oxford University Press, Oxford 1983.

14. WFOT (World Federation of Occupational Therapists). Guidelines for the Development of Curricula for the Education of Rehabilitation Therapists in Developing Countries. (Unpublished document prepared by WFOT Education committee) 1980.

15. WHO Chronicle 31, p. 492.

16. WHO Rehabilitation for all. World Health, May 1984.

\section{Additional References Relating to Rural Disability}

Editorial. Disability: Prevention or containment. International Journal of Epidemiology 1981; 11: 1: 3-4.

Chitti Babu A. Rural rehabilitation - must it remain a theoretical ideal? Rehabilitation in Asia 1980; xxl: 4.38-40

Dick B, Spencer IWF, Watermeyer GS, Bourne DE, Wolff IMF, Moyle GD. Chronic disease in non-institutionalized persons, Part 11, Who cares? S Afr Med J 1978; 53: 918-936.

Hammerman Susan R. Dealing with disability in the developing world: the paradox. World Health 1981; 4-5.

Johnston Mary. The planning dialogue in the community. Contract; February 1978

Gaston Don. Low cost aids, appropriate health resources and technologies, Action Group Ltd. ARHTAG London 1982.

Marghulec 1, Spira E. An approach to the detection of the disabled in a rural area. In: Lees D and Shaw S (eds.).
Impairment, disability and handicap. Heinemann Educational Books, London 1974; pp. 65-77.

Menon PKJ. Light in the darkness. World Health, April 1982; pp. 27-29.

Mia Ahmadallah, Islam Hafizul, Ali Shamsher. Situation of handicapped children in Bangladesh. Assignment Children, 53/54, Spring 1981; 199-217.

Buthelezi Commission; the requirements for stability and development in KwaZulu and Natal, Vol. I and 2. $\mathrm{H}$ \& H Publication Durban, 1982.

Swart HHJ. Die huidige situasie ten opsigte van die praktiese hantering van blindheid in Suid-Afrika. SA Mediese Tydskrif 1981 November.

Sutter EE, Ballard RC. A Community approach to Trachoma control in the Northern Transvaal. S Afr Med J April 1978; 53: 622-625.

McLaren PA. Rural employment of the handicapped in Southern Africa. Paper read in conjunction with William Rowland at the Conference of the S.A. Federal Council for Rehabilitation of the Disabled Swaziland June 1983.

McLaren PA. Motivation for training of multipurpose rehabilitation therapists. Paper read at the SA Congress for people with disabilities, Durban, September 1984.

McLaren PA. The need for a resource document for starting projects for disabled in rural areas. Paper read at the SA Federal Council for Rehabilitation of the Disabled, Johannesburg, August 1984

McLaren PA. Towards employment for rural blind in KwaZulu. IMFAMA 1982; 22: 6.

McLaren PA. The prevalence and impact of motor and ocular disability and impairment in a rural community, and the implications for rehabilitation. Paper presented to the SA Association of Occupational Therapists Congress, Cape Town, July 1985.

Pillay PN. The distribution of medical manpower and health care facilities in South Africa. Carnegie Conference Paper No. 167, Cape Town 1984.

Rehabilitation International, childhood disability: its prevention and rehabilitation. Assignment Children 1981; 53/54: 43-75

Sebina David B, Kgodidinintsi Adelaide Darling. Disability prevention and rehabilitation in Botswana. Assignment Children 1981; 53/54: 135-152.

Sene Pape Marcel. The African experience. World Health 1982.

Sutter EE, Ballard RC. Community participation in the control of Trachoma in Gazankulu. Soc Sci Med 1982; 17(22): 1813-1817.

The Thusanani Association. Venda South Africa. Report, April 1984-March 1985

Wong Wah Tompar-Tiu, Aurora P. A community programme in the Phillipines. Assignment Children 1981; 53/54: $165-183$.

Rehabilitation for all. World Health 1984; May: 1-31.

WHO. The training and utilization of auxiliary personnel for rural health teams in developing countries. Report of a WHO Expert Committee.

WHO Geneva, 7-35.

WHO. Towards a multipurpose rehabilitation therapist. WHO presentation (unpublished document).

United Nations. World programme of action concerning disabled persons. United Nations Decade of Disabled Persons 1983-1992. New York 1983 